\title{
Mathematically engineered stromal cell-derived factor-1 $\alpha$ stem cell cytokine analog enhances mechanical properties of infarcted myocardium
}

\author{
John W. MacArthur, Jr, MD, ${ }^{\text {a }}$ Alen Trubelja, BS, ${ }^{a}$ Yasuhiro Shudo, MD, ${ }^{a}$ Philip Hsiao, BA, ${ }^{a}$

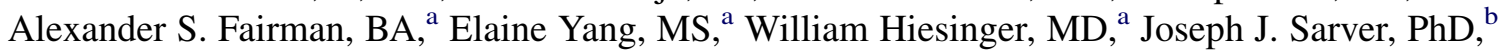 \\ Pavan Atluri, MD, ${ }^{\mathrm{a}}$ and Y. Joseph Woo, MD ${ }^{\mathrm{a}}$
}

\begin{abstract}
Objective: The biomechanical response to a myocardial infarction consists of ventricular remodeling that leads to dilatation, loss of contractile function, abnormal stress patterns, and ultimately heart failure. We hypothesized that intramyocardial injection of our previously designed pro-angiogenic chemokine, an engineered stromal cell-derived factor- $1 \alpha$ analog (ESA), improves mechanical properties of the heart after infarction.
\end{abstract}

\begin{abstract}
Methods: Male rats $(n=54)$ underwent either sham surgery $(n=17)$ with no coronary artery ligation or ligation of the left anterior descending artery $(\mathrm{n}=37)$. The rats in the myocardial infarction group were then randomized to receive either saline $(0.1 \mathrm{~mL}, \mathrm{n}=18)$ or ESA $(6 \mu \mathrm{g} / \mathrm{kg}, \mathrm{n}=19)$ injected into the myocardium at 4 predetermined spots around the border zone. Echocardiograms were performed preoperatively and before the terminal surgery. After 4 weeks, the hearts were explanted and longitudinally sectioned. Uniaxial tensile testing was completed using an Instron 5543 Microtester. Optical strain was evaluated using custom image acquisition software, Digi-Velpo, and analyzed in MATLAB.
\end{abstract}

\begin{abstract}
Results: Compared with the saline control group at 4 weeks, the ESA-injected hearts had a greater ejection fraction $(71.8 \% \pm 9.0 \%$ vs $55.3 \% \pm 12.6 \%, P=.0004)$, smaller end-diastolic left ventricular internal dimension $(0.686 \pm 0.110 \mathrm{~cm}$ vs $0.763 \pm 0.160 \mathrm{~cm}, P=.04)$, greater cardiac output $(36 \pm 11.6 \mathrm{~mL} / \mathrm{min}$ vs $26.9 \pm 7.3$ $\mathrm{mL} / \mathrm{min}, P=.05)$, and a lower tensile modulus $(251 \pm 56 \mathrm{kPa}$ vs $301 \pm 81 \mathrm{kPa}, P=.04)$. The tensile modulus for the sham group was $195 \pm 56 \mathrm{kPa}$, indicating ESA injection results in a less stiff ventricle.
\end{abstract}

Conclusions: Direct injection of ESA alters the biomechanical response to myocardial infarction, improving the mechanical properties in the postinfarct heart. (J Thorac Cardiovasc Surg 2013;145:278-84)

The tissue response to a myocardial infarction (MI) entails far more than the simple conversion of muscle into a hypocontractile scar. Significant interplay also occurs between the ischemic and healthy myocardium. Previous studies have effectively shown that a perfused, yet hypocontractile, border zone is present around the area of an MI and that over time this border zone expands to include previously healthy tissue..$^{1}$ In response to this border zone expansion, ventricular remodeling occurs, including collagen deposition,

From the Division of Cardiovascular Surgery, ${ }^{\text {a }}$ Department of Surgery, University of Pennsylvania School of Medicine, Philadelphia, Pa; and the Penn Center for Musculoskeletal Disorders, ${ }^{\mathrm{b}}$ University of Pennsylvania, Philadelphia, Pa.

This work was supported in part by National Institutes of Health grant 1R01HL089315-01 (to Y.J.W.), National Institutes of Health grant T32 HL007843-15 (to J.W.M.), and American Heart Association Post Doctoral Fellowship grant 12POST11620024 (to J.W.M.).

Disclosures: Authors have nothing to disclose with regard to commercial support.

Read at the 38th Annual Meeting of The Western Thoracic Surgical Association, Maui, Hawaii, June 27-30, 2012.

Received for publication June 26, 2012; revisions received Aug 29, 2012; accepted for publication Sept 12, 2012.

Address for reprints: Y. Joseph Woo, MD, Division of Cardiovascular Surgery, Department of Surgery, University of Pennsylvania School of Medicine, 3400 Spruce St, 6 Silverstein, Philadelphia, PA 19104 (E-mail: wooy@uphs.upenn.edu). $0022-5223 / \$ 36.00$

Copyright (c) 2013 by The American Association for Thoracic Surgery http://dx.doi.org/10.1016/j.jtcvs.2012.09.080 scar formation, myocyte apoptosis, and progressive dilation. ${ }^{2}$ All these characteristics lead to mechanical inefficiency of the ventricle, altered regional stress-strain patterns, and ultimately heart failure, accounting for significant morbidity and mortality.

In an effort to preserve ventricular mechanical properties and prevent the adverse effects associated with remodeling, it would be appealing to institute therapy aimed at limiting the extent of border zone expansion. The endothelial progenitor stem cell cytokine, stromal cell-derived factor- $1 \alpha$ (SDF), has been shown by our group and others to increase neovascularity, decrease border zone expansion, decrease cardiac myocyte apoptosis, and increase cardiac myocyte survival. ${ }^{3-6}$ We have engineered a mathematically designed, supra-efficient analog of SDF-engineered stromal cell-derived factor- $1 \alpha$ stem cell cytokine (ESA) — and demonstrated its in vitro and in vivo potency. ${ }^{7,8}$

Many groups have studied the mechanical properties of ventricular myocardium in various animal models and have shown that infarcts become stiffer over time. ${ }^{9-11}$ To our knowledge, no group has tested the mechanical effect an infarct has on the ventricle as a whole by evaluating the infarct, border zone, and remote tissue simultaneously. In the present study, we hypothesized that intramyocardial 


\section{Abbreviations and Acronyms \\ $\mathrm{ESA}=$ engineered stromal cell-derived factor- $1 \alpha$ analog \\ MI = myocardial infarction \\ $\mathrm{SDF}=$ stromal cell-derived factor- $1 \alpha$}

injection of ESA at the time of MI would limit the amount of ventricular remodeling and preserve the myocardial mechanical properties, leading to more favorable regional stress-strain patterns. We postulated that studying the tensile properties of ventricular muscle strips would yield valuable data and insight into how the infarct affects the remote myocardium.

\section{METHODS}

\section{Protein Design and Synthesis}

We have previously reported on the design and synthesis of ESA. ${ }^{7}$ In brief, the CXCR4 receptor binding $\mathrm{N}$-terminus and the molecularstabilizing $\mathrm{C}$-terminus were preserved and the central $\beta$-pleated sheet was deleted and replaced with 2 proline residues mathematically predicted to retain as similar a 3-dimensional protein configuration to the native SDF as possible. The designed protein was synthesized using solid phase peptide synthesis in which the $\mathrm{N} \alpha$-amino acids are incorporated into the peptide in a stepwise fashion while the terminus is attached to a solid support matrix. After the peptide is complete, it is removed from the polymeric support matrix and lyophilized.

\section{Animal Care and Biosafety}

Male Wistar rats, weighing 250 to $300 \mathrm{~g}$ were obtained from Charles River Labs (Wilmington, Mass). Food and water were provided ad lib. All experiments pertaining to the present investigation conformed to the Guide for the Care and Use of Laboratory Animals, published by the US National Institutes of Health (8th edition, 2011). The Institutional Animal Use and Care Committee of the University of Pennsylvania approved the protocol (no. 803394).

\footnotetext{
Animal Model

MI was induced in 37 male Wistar rats using an established and highly reproducible model. ${ }^{5,6}$ In brief, the rats were anesthetized in a $2 \mathrm{~L}$ induction chamber (VetEquip, Pleasantville, Calif), and 3\% isofluorane was continuously delivered. A 16-gauge angiocatheter was used for endotracheal intubation and connected to mechanical ventilation (Hallowell; EMC, Pittsfield, Mass), with $1 \%$ isofluorane maintained throughout the operation. A thoracotomy was performed through the left fourth intercostal space, the heart was exposed, and a 7-0 polypropylene suture was placed around the left anterior descending artery $2 \mathrm{~mm}$ below the left atrium. The suture was briefly snared to verify the size and location of myocardial ischemia according to color changes and permanently tied down to produce a large anterolateral MI. The rats were then randomized into 2 groups and received 4 separate peri-infarct intramyocardial injections of saline (100 $\mu \mathrm{L}, \mathrm{n}=18)$ or ESA $(6 \mu \mathrm{g} / \mathrm{kg}, \mathrm{n}=19)$. In an additional control group, the rats underwent a sham operation, in which thoracotomy was performed, as above, but no myocardial ischemia was induced $(\mathrm{n}=17)$. The thoracotomy was closed in multiple layers, and tissue adhesive (VetBond; 3M, Minneapolis, Minn) was applied over the incision. All rats were implanted with subcutaneous microchips (BioMedic Data Systems; Boise, Idaho) and allowed to recover from anesthesia. Buprenorphine $(0.5 \mathrm{mg} / \mathrm{kg})$ was administered for postoperative pain control. All 3 groups of rats (sham, saline,
}

and ESA) received subcutaneous injections of granulocyte colonystimulating factor $(40 \mu \mathrm{g} / \mathrm{kg})$ immediately postoperatively.

\section{Echocardiographic and Hemodynamic Assessment}

Left ventricular (LV) geometry and function were evaluated preoperatively and at 4 weeks in all rats. A Phillips Sonos 5500 revD ultrasound system (Philips Medical Systems, Amsterdam, The Netherlands) was used, with a 12-MHz transducer at an image depth of $2 \mathrm{~cm}$. Parasternal LV short axis 2-dimensional and M-mode images at the level of the papillary muscle were used to obtain echocardiographic data. ${ }^{12}$ All analyses were performed by a single investigator, who was unaware of the treatment groups.

Cardiac output was assessed by placing a $2.5-\mathrm{mm}$ periaortic Doppler flow probe (Transonic Systems, Ithaca, NY) around the ascending aorta at the terminal surgery.

\section{Infarct Analysis}

At 4 weeks after the initial operation, the rats were anesthetized and underwent median sternotomy. After the echocardiographic and hemodynamic data had been obtained, the rats were euthanized and the hearts explanted. The atria were removed, and the left ventricle was opened along the posterior septum. Standardized digital photographs were taken with a Nikon D5100 SLR camera (Nikon, Tokyo, Japan). The photographs were uploaded to ImageJ (version 1.46b), and the size of the infarct was assessed with digital planimetry.

In a subset of 9 rats, the hearts were explanted ( 2 in sham, 3 in saline, and 4 in ESA group) and injected retrograde with Tissue Tek OCT compound (Sekura, The Netherlands) through the aorta and pulmonary artery. The hearts were submerged in OCT, frozen, and stored in a $-80^{\circ} \mathrm{C}$ freezer. The orientation of the hearts during freezing was standardized to result in consistent positioning during the sectioning process. Eight, $10-\mu \mathrm{m}$-thick sections were prepared from each heart at the level of the papillary muscles and stained with hematoxylin and eosin or Masson's trichrome stain. Photographs of the border zone were taken using a Leica DFC295 inverted microscope (Leica Microsystems, Wetzlar, Germany) using the $20 \times$ objective. The images were analyzed for infarct collagen content, which turns blue after Masson's trichrome staining, using a custom-made macro in ImageJ.

\section{Mechanical Testing of Ventricular Muscle Strips}

A $15 \mathrm{~mm} \times 3 \mathrm{~mm}$ strip of myocardium was excised from the left ventricle, taken in line with the force vector from apex to base (Figure 1). Polytetrafluoroethylene pledgets were sutured to the ends of the strip with 7-0 polypropylene sutures, and a looped suture was passed through these pledgets to provide a method to mount the specimens (Figure 2). The strips were then placed in a temperature-regulated bath of phosphate-buffered saline maintained at $37^{\circ} \mathrm{C}$. Uniaxial tensile testing was conducted with an Instron 5543 microtester (Instron, Norwood, Mass) with a $10 \mathrm{~N}, 6$-axis load cell (Figure 3). The specimens were preloaded at $0.05 \mathrm{~N}$, followed by 20 cycles of preconditioning at a rate of $0.1 \mathrm{~mm} / \mathrm{s}$ and a load ranging from 0.05 to $0.1 \mathrm{~N}$. After a 60 -s hold at $0.05 \mathrm{~N}, 3$ stress-relaxation phases at incremental displacements of $0.5 \mathrm{~mm}$ were performed, followed by a ramp to failure at $0.1 \mathrm{~mm} / \mathrm{s}$. A custom image acquisition software system (Digi-Velpo, version 1.4.1, run in LabView 2010, National Instruments, Austin, Tex) was used to acquire optical data on tissue displacement. Optical strain data were integrated with the Instron load data using Opticus (custom-made software run in MATLAB, Natick, Mass), which generated stress-strain curves for each ventricular strip.

\section{Statistical Analysis}

Continuous variables are reported as the mean \pm standard deviation. Student $t$ test was used to compare continuous variables. The study was designed with $80 \%$ power to detect a $10 \%$ difference in tensile modulus, with 


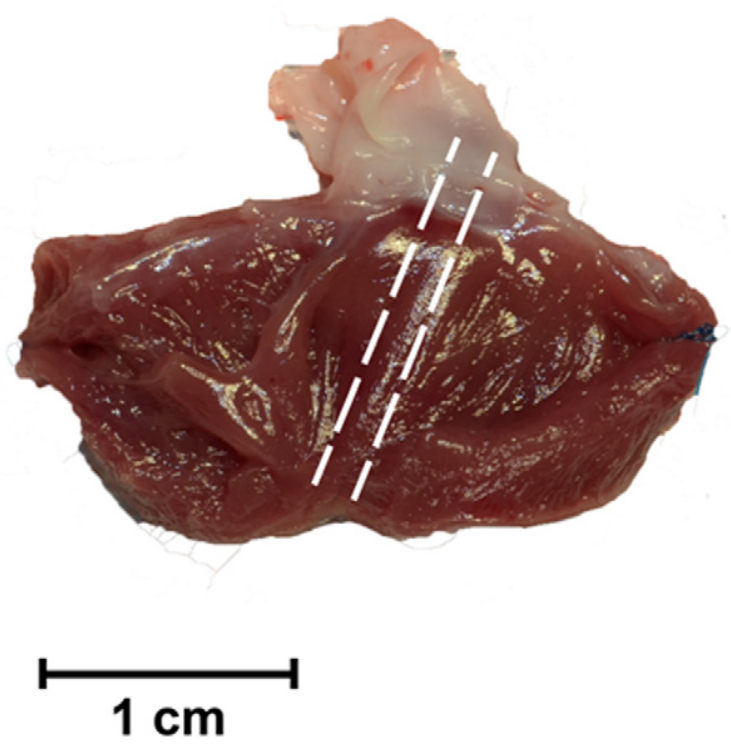

FIGURE 1. Ventricles were opened along the posterior free wall, adjacent to the septum and longitudinally sectioned (white hash marks) for tensile testing.

a standard deviation of $50 \mathrm{kPa}$, requiring 15 animals per group. Statistical significance was set at $P<.05$. The analyses were performed using the STATA statistical software package, version 12.1 (StataCorp, College Station, Tex).

\section{RESULTS}

\section{Infarct Size and Content}

After 4 weeks, the saline and ESA groups had statistically equivalent infarct sizes (saline control, $23.9 \% \pm$ $6.1 \%$; ESA, $20.4 \% \pm 2.8 \% ; P=.1$ ), supporting the reproducibility of this infarct model and consistency between the experimental and control groups. As expected, no infarcts were visualized in the sham group (Figures 4 and 5). The collagen content within the infarct was

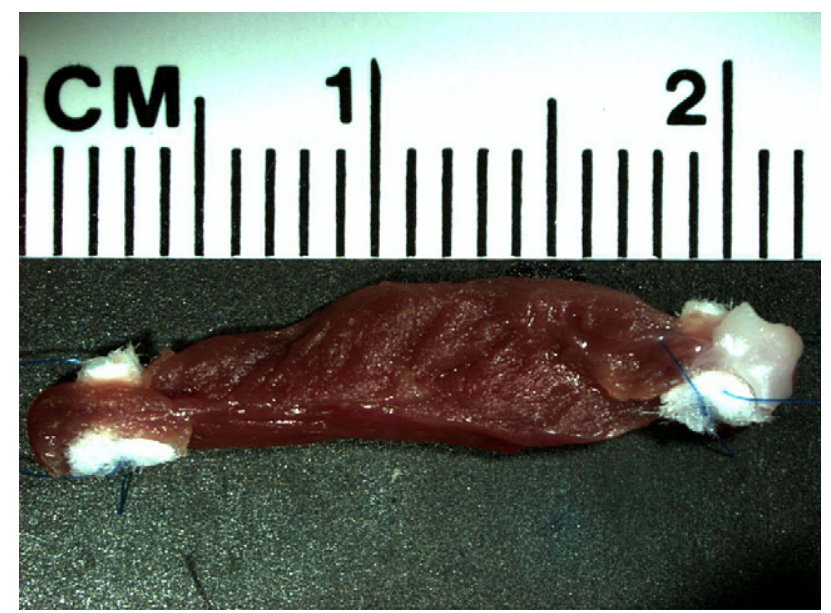

FIGURE 2. Ventricular strip with custom-made polytetrafluoroethylene pledgets reinforcing the edges.

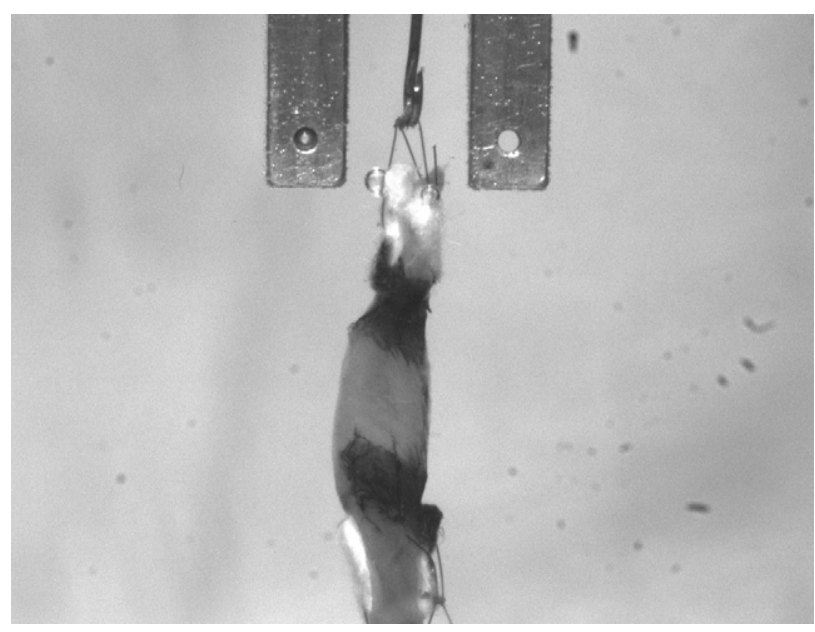

FIGURE 3. Image of ventricular strip inside the temperature-regulated bath, connected to the Instron microtester (Instron, Norwood, Mass).

significantly greater in the saline group than in the ESA group (saline control, $38.6 \% \pm 9.4 \%$; ESA, $30.8 \% \pm$ $5.7 \% ; P=.01$; Figure 6$)$.

\section{Ventricular Remodeling and Function}

The preoperative echocardiographic parameters were not statistically different among the 3 different groups. During the course of 4 weeks, LV dilation occurred in both the ESA and the saline control groups. The saline control group had a statistically significant increase in the LV internal dimension at diastole $(0.763 \pm 0.160$ $\mathrm{cm})$ compared with that in the ESA group $(0.686 \pm$ $0.110 \mathrm{~cm}, P=.04)$ and sham group $(0.539 \pm 0.135$ $\mathrm{cm}, P=.0004)$. As expected with the normal growth of the rat within 4 weeks, a minimal increase was found in the LV internal dimension at diastole of the sham group and the ejection fraction had improved slightly $(82.5 \% \pm 7.5 \%)$. In contrast, in the saline control group, the ejection fraction had decreased significantly during the 4-week course $(55.3 \% \pm 12.6 \%)$, but that in the ESA group was preserved and closer to the preoperative value $(71.8 \% \pm 9.0 \%$; Figure 7$)$. Additionally, a significant decline was seen in the cardiac output of the saline control group $(26.9 \pm 7.3 \mathrm{~mL} / \mathrm{min})$, although the level in the ESA group approached that of the sham group $(36 \pm 11.6 \mathrm{~mL} / \mathrm{min}$ and $37 \pm 7.3 \mathrm{~mL} / \mathrm{min}$, respectively) (Table 1).

\section{Myocardial Mechanical Properties}

The percentage of relaxation was determined from the stress-relaxation cycles obtained during mechanical testing, and no statistically significant differences were found among the 3 groups (sham, $36.4 \% \pm 10.7 \%$; saline control, $38.3 \% \pm 4.6 \%$; and ESA, $38.2 \% \pm 4.4 \%$ ). Finally, the tensile modulus was calculated from the slope of the 


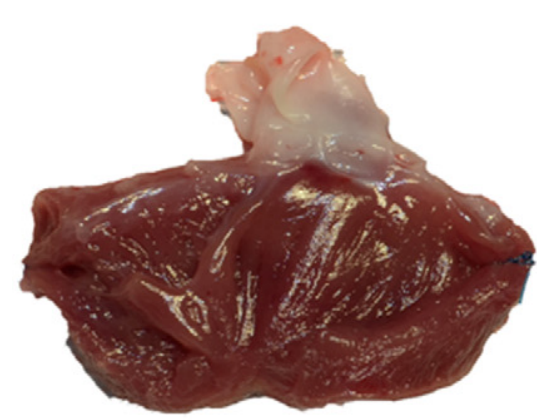

A

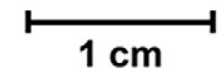

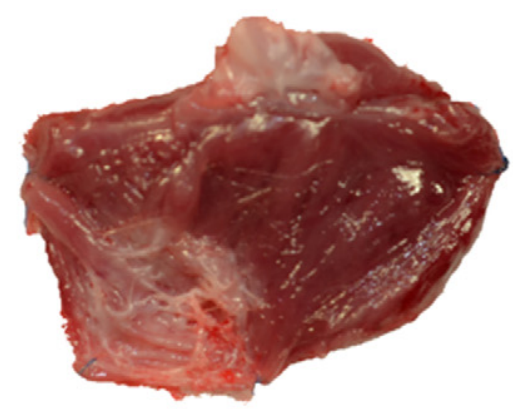

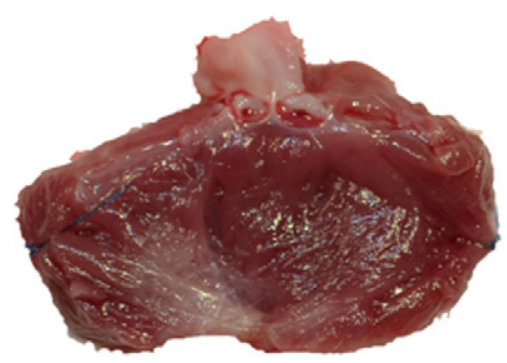

B

C

FIGURE 4. Representative images of infarct sizes. A, Sham operated group, (B) saline control group, and (C) engineered stromal cell-derived factor-1 $\alpha$ analog experimental (ESA) group. Although overall scar area was similar between saline control and ESA groups, it appears that the quality of the scar was different.

stress-strain curves and was found to be significantly greater in the saline control group $(300.8 \pm 81.6 \mathrm{kPa})$ than in the ESA group $(251.5 \pm 56.7 \mathrm{kPa} ; P=.04)$. In contrast, the sham group had a modulus of $195.2 \pm 56.5$ $\mathrm{kPa}$ (Figure 7).

\section{DISCUSSION}

The detrimental effects of border zone expansion on the mechanical properties of the ventricle are well known, and different materials have been delivered intramyocardially in an effort to limit this expansion. ${ }^{13-15}$ Improvements in cardiac function, along with increased vascularity in the border zone, have been shown with various growth factor and cytokine injections. ${ }^{7,8,16-19}$ Our group has specifically shown that the computationally derived, synthesized cytokine ESA is a potent chemokine of bone marrow progenitor cells and is efficacious at preserving ventricular hemodynamics after $\mathrm{MI}$ in an animal model $^{7}$; however, the effects any of these treatments have on the mechanical properties of the global ventricle after infarction are not known.

In the present study, we have shown that injection of ESA into the border zone at MI, not only preserves ventricular function over time, but also leads to an infarct with less collagen and a ventricle with a lower elastic modulus. The histologic analysis leads us to believe that treatment with ESA causes a change in composition of the extracellular matrix within the infarcted myocardium, a finding that might explain the decreased elastic modulus seen in the ESA group compared with the saline control group. Another factor that could potentially explain the change in tensile properties among the groups is elastin content within the extracellular matrix. In a recent study by $\mathrm{Li}$ and colleagues, ${ }^{20}$ rats injected with bone marrow stromal cells transfected with the human elastin gene were effectively shown to preserve ventricular function, reduce scar thickness, and stabilize infarcts without expansion, improvements attributed to overexpression of elastin. Although we did not specifically
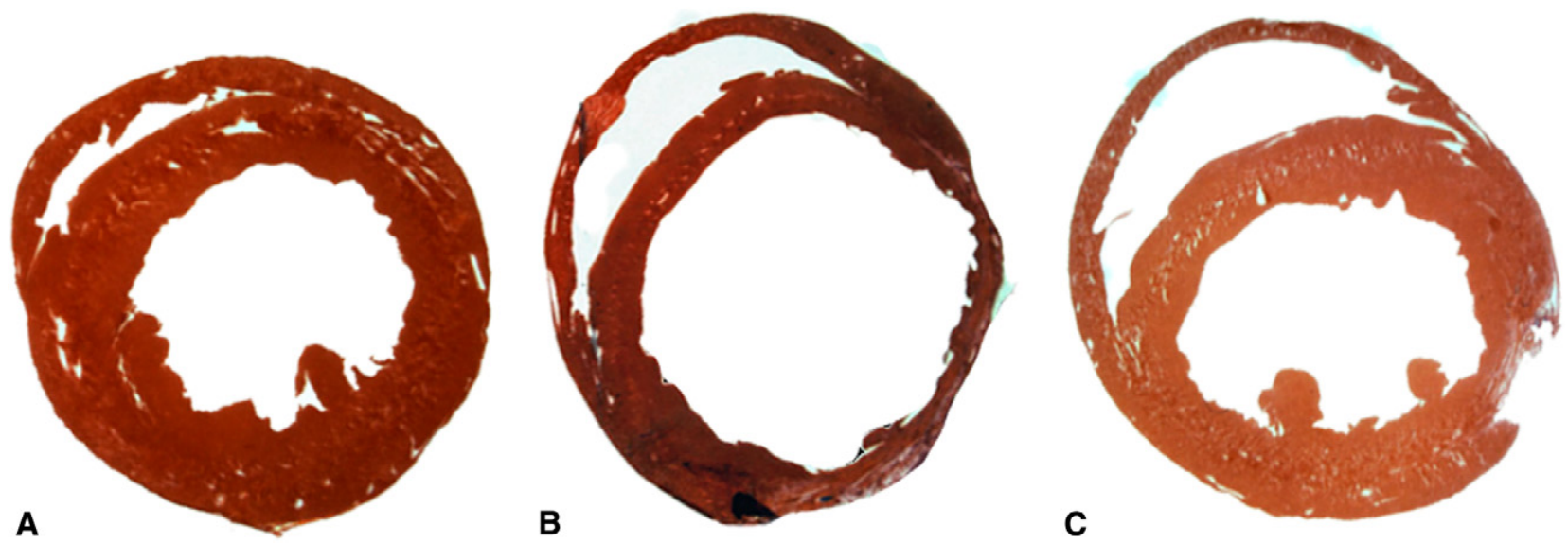

FIGURE 5. Representative cross-sectional images of hematoxylin and eosin-stained section of ventricles from (A) sham group, (B) saline control, and (C) ESA group. 

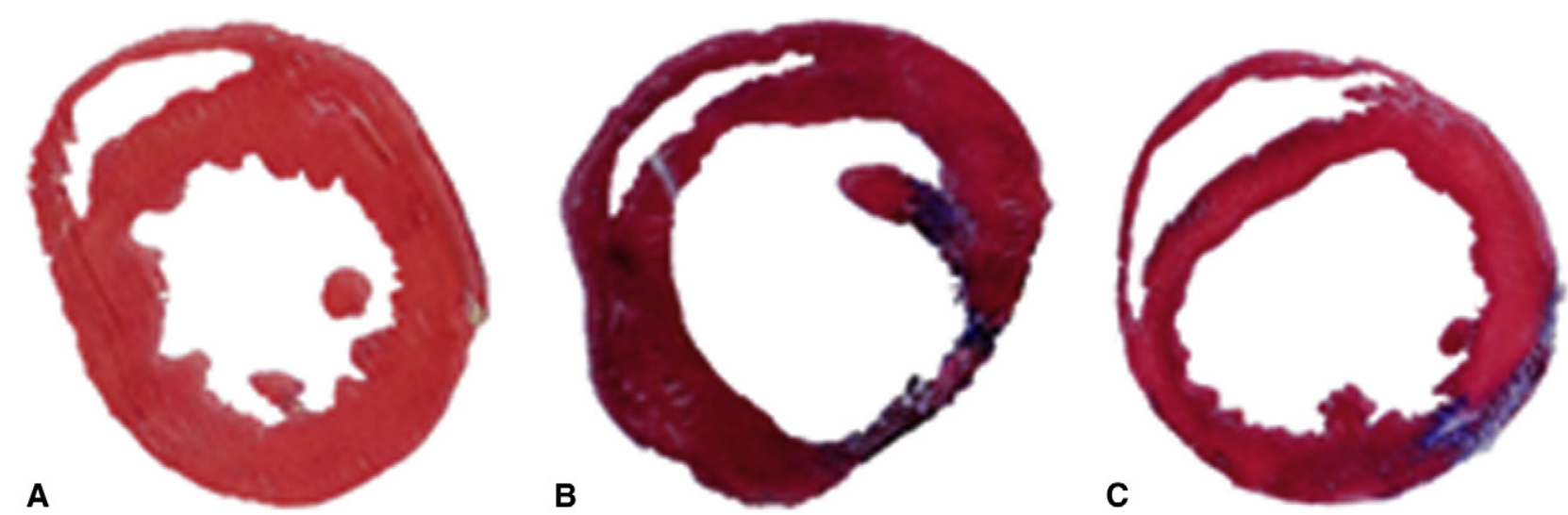

FIGURE 6. Representative cross-sectional images of Masson's trichrome-stained sections of ventricles from (A) sham group, (B) saline control group, and (C) ESA group. On analysis under $20 \times$ objective, infarcts in the ESA group had significantly less collagen than in the saline control group (ESA group, $30.8 \% \pm 5.7 \%$; saline control, $38.6 \% ; P=.01$ ).

evaluate this, it is possible that in the ESA group, bone marrow progenitor cells homed to the ischemic myocardium, preserving the extracellular matrix components and elastin content. Kaushal and colleagues ${ }^{21}$ showed in a study of

\section{Ejection Fraction}

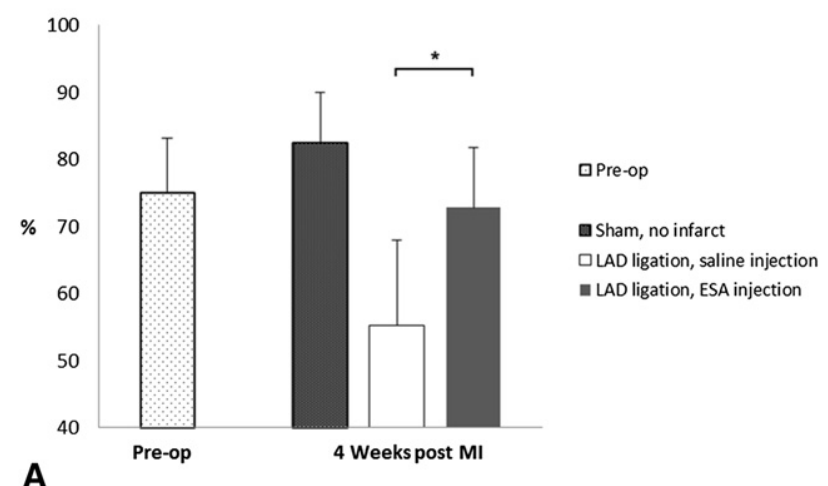

A

\section{Tensile Modulus}

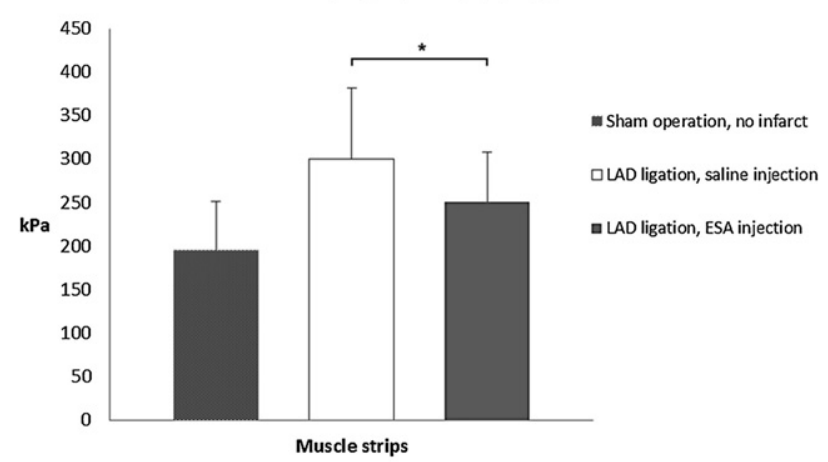

B

FIGURE 7. A, Ejection fraction and (B) tensile modulus of the different groups. ${ }^{*} P<.05$. ESA, Engineered stromal cell-derived factor- $1 \alpha$ analog; $L A D$, left anterior descending (artery); MI, myocardial infarction; Pre-op, preoperative. tissue-engineered, small-caliber blood vessels using endothelial progenitor stem cells, in which grafts seeded with endothelial progenitor stem cells demonstrated preservation of the extracellular matrix, specifically the elastin content.

In contrast to many investigations that have studied specified regions of the ventricle, $, 15,22,23$ we used longitudinal ventricular strips to assess the uniaxial tensile properties encompassing the scar, border zone, and remote tissue in aggregate to understand the stressstrain relationship of the entire ventricle. The results we have reported in the present study correlate well with previous ESA experiments, showing a smaller, less-dilated left ventricle, greater ejection fraction and greater cardiac output compared with the saline control group. ${ }^{8}$ One unique finding from the present study is that treatment with ESA decreased the elastic modulus of the ventricular strip, which can be extrapolated to suggest the entire ventricle is less stiff and similar mechanically to the normal myocardium. These data support our hypothesis that ESA improves the mechanical properties and limits remodeling of the ventricle after infarction. We believe that treatment with ESA preserves ventricular geometry and perfusion, which is inextricably tied to pump efficiency. It is this finding that is of paramount importance in understanding how to optimize the treatment strategy for ischemic heart failure.

The fundamental goal of the present study was to show that injection of ESA improves the mechanics of the postinfarct ventricle. However, also of great importance is the myocyte cellular dynamics occurring at a molecular level between the scar, border zone, and remote myocardium. The data we have reported indirectly support that of other investigations in which injected SDF has been shown to improve the molecular dynamics of the border zone and preserve ventricular function after MI. $^{7,24-26}$ 
TABLE 1. Mechanical and hemodynamic results

\begin{tabular}{lcccc}
\hline \multicolumn{1}{c}{ Variable } & LVIDd $(\mathbf{c m})$ & EF $(\%)$ & Cardiac output $(\mathbf{m L} / \mathbf{m i n})$ & Elastic modulus \\
\hline Preoperative & $0.452 \pm 0.090$ & $75.0 \pm 8.7$ & - & - \\
Sham, no infarction $(\mathrm{n}=17)$ & $0.539 \pm 0.135$ & $82.5 \pm 7.5$ & $37.0 \pm 7.3$ & $195.2 \pm 56.5(\mathrm{n}=15)$ \\
LAD ligation, saline injection & $0.763 \pm 0.160$ & $55.3 \pm 12.6$ & $26.9 \pm 7.3$ & $300.8 \pm 81.6(\mathrm{n}=15)$ \\
$\quad(\mathrm{n}=18)$ & & & & \\
LAD ligation, ESA injection & $0.686 \pm 0.110 ; P=.04^{*}$ & $71.8 \pm 9.0 ; P=.0004^{*}$ & $36.0 \pm 11.6 ; P=.05^{*}$ & $251.5 \pm 56.7(\mathrm{n}=15) ; P=.04^{*}$ \\
$\quad(\mathrm{n}=19)$ & & & & \\
\hline
\end{tabular}

$E F$, Ejection fraction; $E S A$, engineered stromal cell-derived factor- $1 \alpha$ analog; $L A D$, left anterior descending (artery); $L V I D d$, left ventricular internal dimension at diastole. ${ }^{*}$ Compared with saline control group.

Although we have shown a statistically significant reduction in the elastic modulus of the ventricular strips treated with ESA, with good confidence intervals for each specimen sampled, our study had some limitations. First, our technique for obtaining the stress-strain relationships was through uniaxial testing from longitudinally sectioned ventricle. This leaves out the circumferential strain, which is also important to consider when determining the overall elastic modulus of the tissue. An additional shortcoming of uniaxial testing is its inability to characterize the material properties as either isotropic or anisotropic. This will be solved by performing biaxial testing on the strips. The second limitation we have identified is that the myocyte directionality was not determined before testing was performed. If alignment of myocytes within a sample was known, the theoretical modulus of the tissue could have been obtained. However, we sectioned the ventricular strips to be in line with the summative force vector of the ventricle, which was standardized across all groups.

In conclusion, improvements in the mechanical properties and reduced remodeling of the ventricle can be achieved with ESA therapy after MI, resulting in improved hemodynamics. The effects of ESA on the ventricle are multifactorial and likely a result of limiting expansion of the border zone, preserving the extracellular matrix within the infarct, and optimizing the remaining normal myocardium.

\section{References}

1. Jackson BM, Gorman JH, Moainie SL, Guy TS, Narula N, Narula J, et al. Extension of border zone myocardium in postinfarction dilated cardiomyopathy. $J \mathrm{Am}$ Coll Cardiol. 2002;40:1160-71.

2. Yankey GK, Li T, Kilic A, Cheng G, Satpute A, Savai K, et al. Regional remodeling strain and its association with myocardial apoptosis after myocardial infarction in an ovine model. J Thorac Cardiovasc Surg. 2008;135: 991-8.

3. Unzek S, Zhang M, Mal N, Mills WR, Laurita KR, Penn MS. SDF-1 recruits cardiac stem cell-like cells that depolarize in vivo. Cell Transplant. 2007;16: 879-86.

4. Hatzistergos KE, Quevedo H, Oskouei BN, Hu Q, Feigenbaum GS, Margitich IS, et al. Bone marrow mesenchymal stem cells stimulate cardiac stem cell proliferation and differentiation. Circ Res. 2010;107:913-22.

5. Atluri P, Liao GP, Panlilio CM, Hsu VM, Leskowitz MJ, Morine KJ, et al. Neovasculogenic therapy to augment perfusion and preserve viability in ischemic cardiomyopathy. Ann Thorac Surg. 2006;81:1728-36.
6. Woo YJ, Grand TJ, Berry MF, Atluri P, Moise MA, Hsu VM, et al. Stromal cell-derived factor and granulocyte-monocyte colony-stimulating factor form a combined neovasculogenic therapy for ischemic cardiomyopathy. $J$ Thorac Cardiovasc Surg. 2005;130:321-9.

7. Hiesinger W, Perez-Aguilar JM, Atluri P, Marotta NA, Frederick JR, Fitzpatrick JR III, et al. Computational protein design to reengineer stromal cell-derived factor-1alpha generates an effective and translatable angiogenic polypeptide analog. Circulation. 2011;124(11 Suppl):S18-26.

8. Hiesinger W, Frederick JR, Atluri P, McCormick RC, Marotta N, Muenzer JR, et al. Spliced stromal cell-derived factor-1alpha analog stimulates endothelial progenitor cell migration and improves cardiac function in a dose-dependent manner after myocardial infarction. J Thorac Cardiovasc Surg. 2010;140: 1174-80.

9. Gupta KB, Ratcliffe MB, Fallert MA, Edmunds LH Jr, Bogen DK. Changes in passive mechanical stiffness of myocardial tissue with aneurysm formation. Circulation. 1994;89:2315-26.

10. Lerman RH, Apstein CS, Kagan HM, Osmers EL, Chichester CO, Vogel WM, et al. Myocardial healing and repair after experimental infarction in the rabbit Circ Res. 1983;53:378-88.

11. Connelly CM, Vogel WM, Wiegner AW, Osmers EL, Bing OH, Kloner RA, et al. Effects of reperfusion after coronary artery occlusion on post-infarction scar tissue. Circ Res. 1985;57:562-77.

12. Brown L, Fenning A, Chan V, Loch D, Wilson K, Anderson B, et al. Echocardiographic assessment of cardiac structure and function in rats. Heart Lung Circ. 2002;11:167-73.

13. Ifkovits JL, Tous E, Minakawa M, Morita M, Robb JD, Koomalsingh KJ, et al Injectable hydrogel properties influence infarct expansion and extent of postinfarction left ventricular remodeling in an ovine model. Proc Natl Acad Sci U S A. 2010;107:11507-12

14. Ryan LP, Matsuzaki K, Noma M, Jackson BM, Eperjesi TJ, Plappert TJ, et al. Dermal filler injection: a novel approach for limiting infarct expansion. Ann Thorac Surg. 2009;87:148-55.

15. Morita M, Eckert CE, Matsuzaki K, Noma M, Ryan LP, Burdick JA, et al. Modification of infarct material properties limits adverse ventricular remodeling. Ann Thorac Surg. 2011;92:617-24.

16. Berry MF, Engler AJ, Woo YJ, Pirolli TJ, Bish LT, Jayasankar V, et al. Mesenchymal stem cell injection after myocardial infarction improves myocardial compliance. Am J Physiol Heart Circ Physiol. 2006;290:H2196-203.

17. Jayasankar V, Woo YJ, Pirolli TJ, Bish LT, Berry MF, Burdick J, et al. Induction of angiogenesis and inhibition of apoptosis by hepatocyte growth factor effectively treats postischemic heart failure. J Card Surg. 2005;20: 93-101.

18. Jayasankar V, Bish LT, Pirolli TJ, Berry MF, Burdick J, Woo YJ. Local myocardial overexpression of growth hormone attenuates postinfarction remodeling and preserves cardiac function. Ann Thorac Surg. 2004;77:2122-9.

19. Woo YJ, Panlilio CM, Cheng RK, Liao GP, Suarez EE, Atluri P, et al. Myocardial regeneration therapy for ischemic cardiomyopathy with cyclin A2.J Thorac Car diovasc Surg. 2007;133:927-33.

20. Li SH, Sun Z, Guo L, Han M, Wood MF, Ghosh N, et al. Elastin overexpression by cell-based gene therapy preserves matrix and prevents cardiac dilation. $J$ Cell Mol Med. 2012;16:2429-39.

21. Kaushal S, Amiel GE, Guleserian KJ, Shapira OM, Perry T, Sutherland FW, et al Functional small-diameter neovessels created using endothelial progenitor cells expanded ex vivo. Nat Med. 2001;7:1035-40.

22. Przyklenk K, Connelly CM, McLaughlin RJ, Kloner RA, Apstein CS. Effect of myocyte necrosis on strength, strain, and stiffness of isolated myocardial strips. Am Heart J. 1987;114:1349-59. 
23. Heller LJ, Mohrman DE, Prohaska JR. Decreased passive stiffness of cardiac myocytes and cardiac tissue from copper-deficient rat hearts. Am J Physiol Heart Circ Physiol. 2000;278:H1840-7.

24. Zhang M, Mal N, Kiedrowski M, Chacko M, Askari AT, Popovic ZB, et al. SDF-1 expression by mesenchymal stem cells results in trophic support of cardiac myocytes after myocardial infarction. FASEB J. 2007;21:3197-207.
25. Dong F, Harvey J, Finan A, Weber K, Agarwal U, Penn MS. Myocardial CXCR4 expression is required for mesenchymal stem cell mediated repair following acute myocardial infarction. Circulation. 2012;126:314-24.

26. Kuraitis D, Zhang P, McEwan K, Zhang J, McKee D, Sofrenovic T, et al. Controlled release of stromal cell-derived factor-1 for enhanced progenitor response in ischemia. J Control Release. 2011;152(Suppl 1):e216-8. 